\title{
Domestication in Real Time: The Curious Case of a Trigenomic Sunflower Population
}

\author{
Jill M. Ekar ${ }^{1, *} \mathbb{C}$, Kevin J. Betts ${ }^{2}$, Adam C. Herman ${ }^{1}$, Robert M. Stupar ${ }^{2}{ }^{(}$, Donald L. Wyse ${ }^{2}$, \\ Yaniv Brandvain ${ }^{1}$ and Michael B. Kantar ${ }^{3}$ (D) \\ 1 Department of Plant and Microbial Biology, University of Minnesota, 123 Snyder Hall, 1475 Gortner Ave, \\ Saint Paul, MN 55108, USA; aherman@umn.edu (A.C.H.); ybrandva@umn.edu (Y.B.) \\ 2 Department of Agronomy and Plant Genetics, University of Minnesota, 411 Borlaug Hall, \\ 1991 Upper Buford Circle, St. Paul, MN 55108, USA; betts003@umn.edu (K.J.B.); \\ stup0004@umn.edu (R.M.S.); wysex001@umn.edu (D.L.W.) \\ 3 Department of Tropical Plant \& Soil Sciences, St. John Plant Science Lab, Room 102, University of Hawaii, \\ 3190 Maile Way, Honolulu, HI 96822, USA; mbkantar@hawaii.edu \\ * Correspondence: jmekar@umn.edu; Tel.: +16-126-246-774
}

Received: 27 September 2019; Accepted: 27 October 2019; Published: 31 October 2019

\begin{abstract}
This study chronicles the ongoing process to domesticate an interspecific trigenomic tetraploid hybrid sunflower derived from a series of interspecific crosses between Helianthus annuиs and Helianthus tuberosus. The goal of this process is to develop a perennial oilseed crop that can produce both high value vegetable oil and continuous ground-cover. Selection has focused on developing an ideotype with the domesticated morphology of $H$. annuus and the below-ground perennial features of $H$. tuberosus. The overarching challenge in the process of breeding and domesticating this interspecific perennial sunflower is overcoming obstacles associated with interploid meiosis in order to resolve a chromosomally stable hybrid population. As selection progresses through generations of intermating, there are improvements toward the desired ideotype, but selection efficiency is slowed by apparent antagonisms between annual- and perennial morphological targets and irregular meiosis which is especially problematic in a trigenomic tetraploid. This shows that keys toward perennial crop development through interspecific hybridization will be to capitalize on the abundant phenotypic variation within our population, achieve meiotic stability in order to maximize selection efficiency, and to break genetic correlations between annual and perennial traits.
\end{abstract}

Keywords: Helianthus; wide hybridization; perennial crop; fertility; meiosis; ideotype; polyploidy; domestication

\section{Introduction}

As the world population continues to grow, approaching ten billion people by 2050, improved crops will be required to not only meet the demands for food, fiber and fuel, but also to be managed in a sustainable way to protect both our topsoil and our waterways [1,2]. Breeding crops for the future requires not only maintaining yields, but also advancing cropping systems that will help preserve our soil and water in the face of climate change [3]. Sustainable agricultural practices have been widely adopted [4,5], but adoption is balanced with economics [6]. Changing economics require a broader suite of potential crops for sustainable practices, and recent work has shown an increased interest in the development and production of perennial crops [7]. Adoption rates differ globally, with perennial crops generally being more popular in European countries [5].

Perennial crops fit the desire for sustainable practices as they require less water and sequester a greater amount of atmospheric carbon [8-10], which may make them more tolerant to new abiotic 
stresses brought on by climate change while helping to offset its impacts [11-13]. Perennial crops' persistence year-to-year reduces carbon inputs from tilling while protecting the soil from wind [14] and water erosion [15]. Year-round ground covers capitalize on Spring and Fall moisture inputs and nutrients that would normally be lost $[10,16]$.

Human cultures have domesticated hundreds of plants [17], and the process of domestication is well studied, e.g., [18-20]. Several notable successes in sustainable crop breeding have been made in perennial, winter annual, and bioenergy plant domestication [21-23]. The most notable example is intermediate wheatgrass, which is now used by restaurateurs, breweries and food processors [24]. In addition to intermediate wheatgrass, there are efforts to domesticate many different perennial crops such as silphium [25], flax, interspecific hazelnuts [26], various forages [27], and even willow and poplar trees $[28,29]$.

This study aims to chronicle the domestication of an interspecific trigenomic tetraploid sunflower, Helianthus annuus $\times$ Helianthus tuberosus. The annual sunflower, $H$. annuus, is valued for its high-quality vegetable oil and consumable seeds, and has a domesticated morphology that is desirable for harvesting (i.e., a single large head containing large seeds), while H. tuberosus, known as Jerusalem artichoke, displays perenniality through vigorous production of elongated tubers. In their hybrids, tuber formation is necessary for perennaility, however, tuber formation does not guarantee perenniality. Maintaining this population for 17 years has demonstrated that in order for a plant to be perennial, it must both form tubers and show cold tolerance [30,31]. Attempts have been made to stabilize crosses between these species since the 1930s in order to transmit pest resistance genes or perenniality from $H$. tuberosus to the cultivated sunflower through wide hybridization and serial backcrossing, but fertility issues have consistently stymied progress [30,32-39].

The principal goal within the $H$. annuus $\times H$. tuberosus breeding program is to combine perenniality and cold-hardy traits of hexaploid $H$. tuberosus with the favorable agronomic traits of the diploid domestic sunflower, and do so while overcoming obstacles associated with problematic interploid meiosis in order to resolve a chromosomally stable population. Hybrid sunflowers in this breeding program are the progeny of tetraploid $\mathrm{F}_{1}$ hybrids created by crossing Helianthus tuberosus and Helianthus annuus [39]. Perennial $H$. tuberosus is an autoallohexaploid $\left(\mathrm{A}_{1} \mathrm{~A}_{1} \mathrm{~A}_{2} \mathrm{~A}_{2} \mathrm{BB}: 2 n=6 x=102\right.$; [33] containing two sets of chromosomes from $H$. divaricatus (the " $\mathrm{A}$ " genomes), and a single set from Helianthus grosseserratus (the " $\mathrm{B}$ " genome) [40]. The other parent is the annual sunflower, H. annuus (the " $\mathrm{C}$ " genome, $2 n=2 x=34$ ). Thus the initial breeding population contained contributions of three ancestral species, thought to be in an "AA BC" arrangement [31]. It has been hypothesized that when meiosis proceeds normally, new generations should tend to have a complement of two H. divaricatus, one $H$. grosseserratus, and one $H$. annuus genomes (AA BC: $2 n=4 x=68$ ).

We select plants based on an ideal set of morphological traits, or "ideotype" [41], including head size, seed size, apical dominance (i.e., the suppression of axillary flowers) and tuber production. Since our hybrid sunflowers contain four subgenomes, we also selected for a tetraploid genome size with the aim of improving genomic stability and thus, fertility. All ideotype traits are intermediate but highly variable in the hybrids [31], allowing selection to advance. Here, we present results from selection spanning six generations of hybrid sunflowers. We show some progress in ideotype traits, however we also show that perennial and annual traits are negatively correlated. As such, selection efforts should focus on achieving meiotic stability that approaches that of established polyploid populations while simultaneously breaking the genetic correlation between annual and perennial traits to establish a perennial crop.

\section{Materials and Methods}

\subsection{Population Development}

The population described in this work is derivative of the population described in [30] and [31], which derives from an initial population of 187 interspecific $F_{1}$ hybrids of the annual sunflower, 
$H$. annuus and a perennial sunflower, $H$. tuberosus. Initial $F_{1}$ hybrids were formed by crossing 18 local wild-collected $H$. tuberosus parents (all collected within five miles of the field site) with three inbred lines of $H$. annuus, including CMS HA 89 (PET1 cytoplasmic male sterility), HA 89 (released by the USDA ARS in 1971), and HA 434 [42]. These $\mathrm{F}_{1} \mathrm{~s}$ were intermated (IM: using bulked pollen from the population's top domestication candidates) to form a population designated " $\mathrm{IM}_{1} \mathrm{~F}_{1}$ ", with subsequent intermated generations designated " $\mathrm{IM}_{2} \mathrm{~F}_{1}$ ", then " $\mathrm{IM}_{3} \mathrm{~F}_{1}$ ", and so on. This work describes breeding efforts and observations starting with 18 individuals selected from the $\mathrm{IM}_{3} \mathrm{~F}_{1}$ population, tracking their derivative generations through $\mathrm{IM}_{8} \mathrm{~F}_{1}$ (2018). Generations are overlapping, as intermating used the mixed pollen of verified tetraploid plants from available generations $\mathrm{IM}_{3} \mathrm{~F}_{1}$ through $\mathrm{IM}_{7} \mathrm{~F}_{1}$ (Pedigree in Figure 1). While all perennial plants were saved, only plants with desirable ideotype traits (large seeds, large heads, and apical dominance) were selected as parents for subsequent generations.

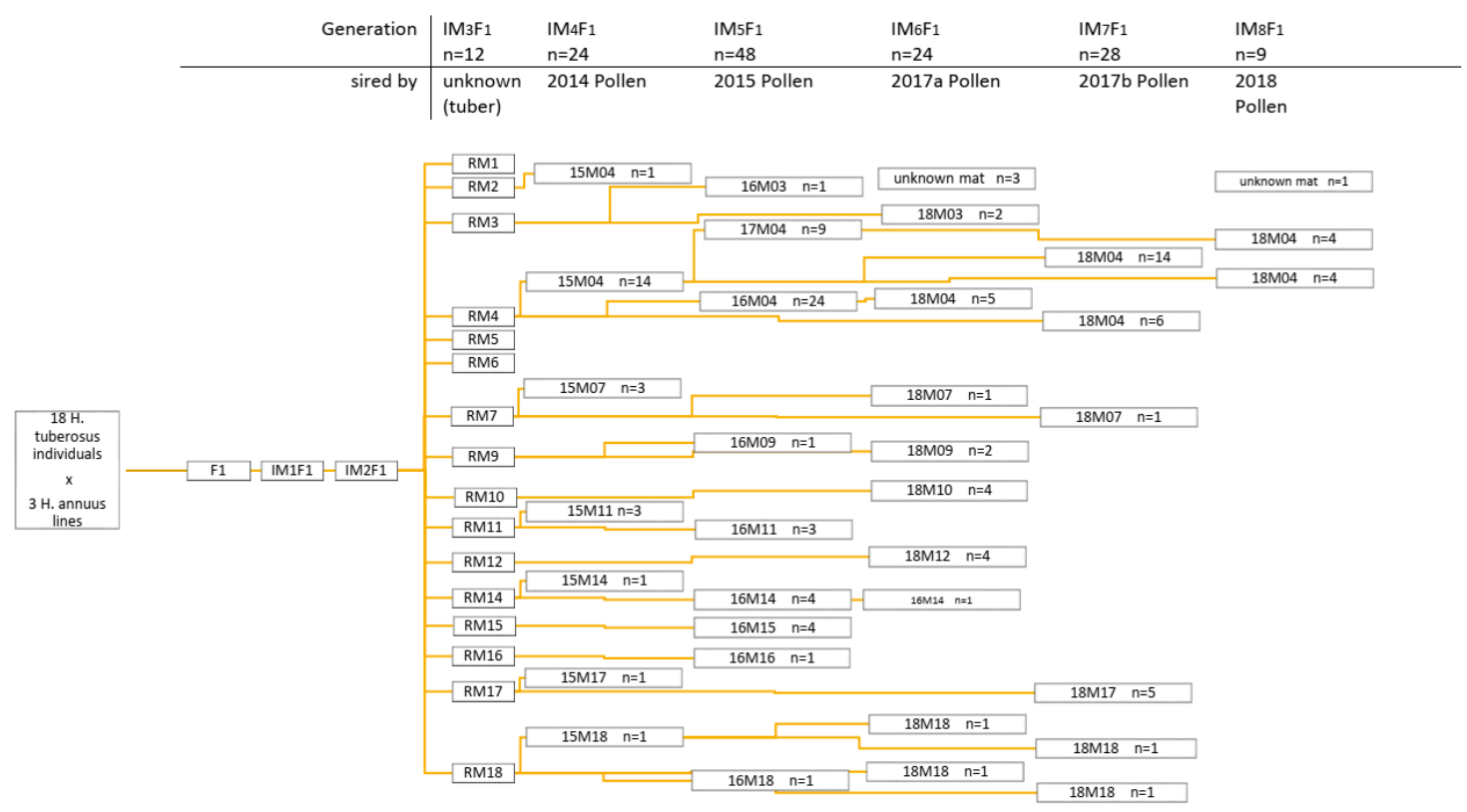

Figure 1. Pedigree of maternal lines continued in the intermated (IM) generations. Parents and $\mathrm{F}_{1}$ populations were previously phenotyped for perenniality and domestication syndrome traits including seed size, branching, pollen fertility, head diameter, and number of heads [31]. Initial populations were selected based on a domestication syndrome trait index developed to move the population toward the perennial sunflower ideotype [30]. For the first three generations this index was used to select the top twenty percent of the maternal half sib families for inclusion in the next generation of plant material. After the $\mathrm{IM}_{3} \mathrm{~F}_{1}$ generation, selection was based on theoretical fertility, as seed production was the limiting factor in the ability to move toward commercialization. The individuals in the $\mathrm{IM}_{3} \mathrm{~F}_{1}$ generation were designated random mated (RM) as all previous selected lines were grown in the same field and pollen control was not used. Downstream progeny is given pooled identifiers here based on the year they were produced, the breeder's ID, and their maternal line. Each pooled ID is connected to its maternal ID (individual or pooled) by yellow lines and situated under the corresponding pollen donor cohort. Sample sizes are provided for each pooled ID. We note the four individuals with unknown maternity (i.e., seeds that escaped their individual envelope during collection).

Each Spring from 2015-2018, tubers from all winter-hardy plants from $\mathrm{IM}_{3} \mathrm{~F}_{1}$ to the latest generation were outplanted to well-drained Waukegan silt loam soil in Rosemount, $\mathrm{MN}$ (located at $44^{\circ} 44^{\prime} \mathrm{N}$ $93^{\circ} 01^{\prime} \mathrm{W}$ ) where they were maintained and cross pollinated. At the end of each growing season, seed from the summer crosses along with any tubers from the field were harvested and relocated to greenhouse facilities where they were sown in autoclaved field soil in $15 \mathrm{~cm}$ pots. These plants were maintained in the greenhouse throughout the winter where additional crosses were conducted and resulting seeds were sown as above until Spring planting. 


\subsection{Flow Cytometry}

Fresh leaves from 30 individuals spanning generations $\mathrm{IM}_{3} \mathrm{~F}_{1}$ through $\mathrm{IM}_{7} \mathrm{~F}_{1}$, as well as fresh samples of $H$. annuus and $H$. tuberosus (parental diploid and hexaploid standards, respectively), were sent to Benaroya Research Institute at Virginia Mason, Seattle, WA for flow cytometric estimation of nuclear DNA content. Genome sizes were assayed four times for a single leaf per individual using chicken red blood cells as an internal standard. We then compared individual hybrid genome measurements to those of parental species with known ploidies to determine ploidy in each hybrid individual.

\subsection{Phenotyping}

Plants were scored for eight traits which are outlined with their phenotyping procedures and sample size per generation in Table 1. In their first growing season, individuals were measured for floral, seed, and perenniality traits (although the initial $\mathrm{IM}_{3} \mathrm{~F}_{1}$ generation was grown from tubers, not seed, in their "first" season). Since no evidence of cold-hardiness among non-tuber bearing plants exists [30,31], individuals were discarded if they lacked perennial organs at the end of the first growing season or if they failed to survive the winter. Pollen traits were analyzed from all available samples in the summer of 2017.

Pollen samples were stained using the protocol of Peterson et al. [43], then sealed under a cover-slip on a glass slide. These samples were magnified at $200 \times$ using a Nikon Eclipse E600 transmission light microscope, then photographed with an iPhone6 camera (Figure 2A). Pollen grains containing cytoplasm should imbibe stain, but it should be noted that the presence of cytoplasm is an overestimate of viability as it does not necessarily guarantee stability or compatibility in actual pollination. For instance, some grains were extremely large, implicating non-reduction or cytomixis during meiosis [44], either of which could render pollination unsuccessful. Therefore, we considered the variance of pollen diameter as a more reliable indicator of male fertility, and pollen staining as supporting evidence. Pollen staining provides a link to previous work on interspecific Helianthus populations as well as a way to understand how this interspecific population compares to its progenitor species.

Table 1. This table describes the methodology for each phenotype measurement and displays the sample sizes of traits measured for each generation.

\begin{tabular}{|c|c|c|c|c|c|c|c|}
\hline & \multirow[t]{2}{*}{ Description } & \multicolumn{6}{|c|}{$\begin{array}{c}\text { Sample Size }(n) \text { for a Specified IM } \\
\text { Generation }\end{array}$} \\
\hline & & 3 & 4 & 5 & 6 & 7 & 8 \\
\hline Perenniality & $\begin{array}{l}\text { A score from zero (annual: zero tuber presence) to } \\
\text { five. A score of at least one implies that, minimally, } \\
\text { a single shoot survived the first winter, with } \\
\text { increasing scores indicating more abundant tubers } \\
\text { with a stronger resemblance to those of H. tuberosus; } \\
\text { Figure } 4 \mathrm{~A} \text {. }\end{array}$ & 12 & 24 & 47 & 22 & 16 & 9 \\
\hline Seed width & The average widths of three seeds per plant. & 12 & 22 & 25 & 8 & 16 & 9 \\
\hline Disk diameter & The average diameter of composite heads of a plant. & 12 & 23 & 43 & 24 & 18 & 9 \\
\hline $\begin{array}{l}\text { Heads per } \\
\text { plant }\end{array}$ & $\begin{array}{l}\text { A measure of apical dominance, with more heads } \\
\text { indicating less apical dominance. }\end{array}$ & 12 & 23 & 43 & 24 & 18 & 9 \\
\hline $\begin{array}{l}\text { Seeds per } \\
\text { head }\end{array}$ & $\begin{array}{l}\text { The average seeds per head of a plant. We use seeds } \\
\text { per head as our metric for seed set and female } \\
\text { fertility. }\end{array}$ & 12 & 23 & 43 & 24 & 18 & 9 \\
\hline $\begin{array}{l}\text { Pollen } \\
\text { staining }\end{array}$ & Proportion (of 50) stained pollen grains of a plant. & 6 & 16 & 42 & 2 & 0 & 0 \\
\hline $\begin{array}{l}\text { Pollen size } \\
\text { variance }\end{array}$ & $\begin{array}{l}\text { Pollen diameter variance was determined for the } \\
\text { same } 50 \text { pollen grains per individual using ImageJ } \\
\text { software. }\end{array}$ & 6 & 16 & 42 & 2 & 0 & 0 \\
\hline
\end{tabular}


A) Example pollen microscopy images

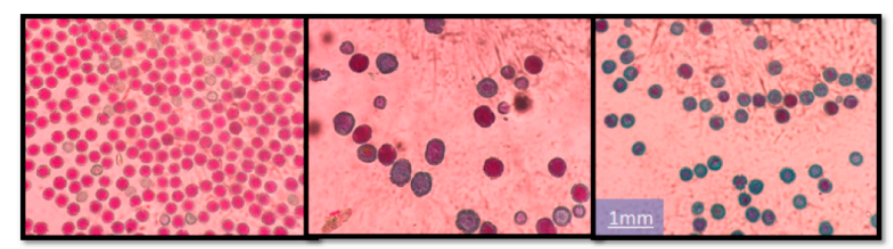

A1) Good staining, regular shape (H. annuus). A2) Good staining, irregular shape (Hybrid). A3) Poor staining, regular shape (Hybrid).
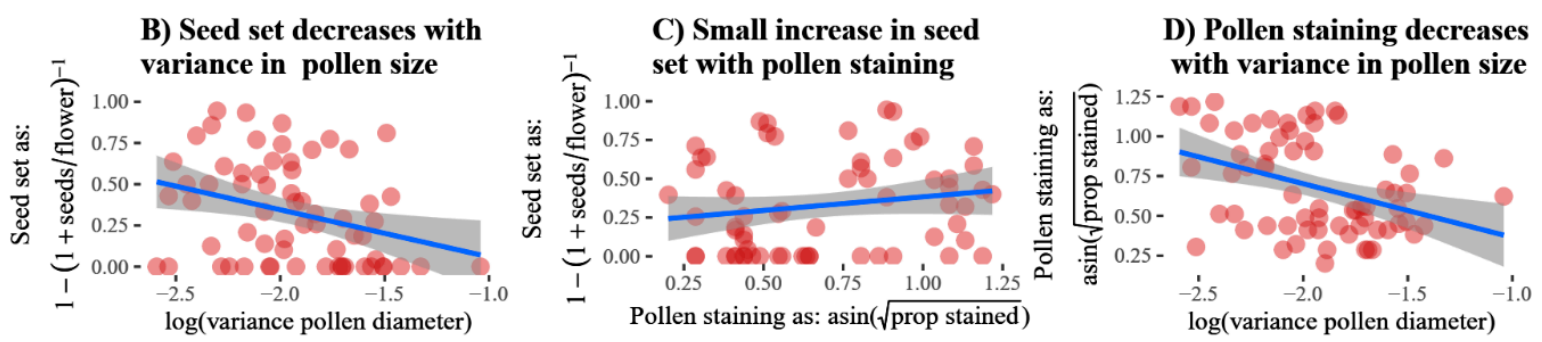

Figure 2. Fertility traits (A) as seen in pollen samples of $H$. annuus and $H$. annuus $\times H$. tuberosus hybrids and (B-D) compared across female and male fertility metrics.

\subsection{Statistical Analyses}

Phenotypic regressions were calculated for all traits of interest. Disk diameter, the variance on pollen diameter, and heads per plant were all log transformed, and perennial index was transformed with $\log +1$. We calculated the deviation from tetraploidy using $\sqrt{ }\left((x-4)^{2}\right)$ where $x$ is the estimated ploidy for an individual, and we transformed the number of seeds per head using $(1-(1 /(x+1)))$. We used the arcsine of the square root transformation for pollen staining. Each fertility and morphological trait was compared via linear regression, then each trait was regressed across generations to assess its trajectory. We also used linear regressions to compare each trait to the deviation from $4 x$ ploidy. We used ANOVAs to look for trait differences between generations and between maternal lines. We use Spearman's rank correlation to correct for disk size as a potential confounding factor in analyses where female fertility and male fertility appear to disagree. Specifically, we used a nonparametric test of the correlation between variance in pollen size and seeds per head divided by disk area. $\mathrm{R}$ code for these analyses can be found in Methods S1. These calculations were done using the statistical software R [45]. Further, relationships between phenotypes were assessed for implications related to breeding. For example, if pollen and stylar fertility are unrelated, we would need to select on both independently, while if these traits were positively (genetically) correlated, selection on pollen or stylar fertility would result in a response to selection on both. However, we consider the possibility that male and female fertility could be antagonistic to one another, due to both complications of interploid meiosis and because the original population used to create $\mathrm{F}_{1}$ hybrids included an $H$. annuus line with cytoplasmic male sterility. We also examine the correlation between fertility and traits of agronomic interest; such correlations again, could impact breeding design. For example, if a negative relationship exists, selection will progress more slowly.

While these data could be analyzed as a random effects model with maternal line as a random effect, the population structure would make for a quite complex analysis and interpretation. For simplicity, we therefore perform standard linear models (e.g., without including maternal line as a random effect).

\section{Results}

\subsection{Trait Relationships with Fertility}

We first evaluate the association between pollen staining and uniformity of pollen size as measures of pollen viability. In contrast to $H$. annuus which has high pollen stainability and low individual variance in pollen diameter (staining $=93 \%$, average variance $=4 \mathrm{~nm}$ ), hybrid pollen is much less viable (staining average: $41 \%$, range: $4 \%-88 \%$; average variance: $15 \mathrm{~nm}$, range: $3-91 \mathrm{~nm}$; Figure $2 \mathrm{a}$ ). 
Pollen stainability and pollen size variance show a negative relationship (slope $=-0.15, r^{2}=0.14$, $t=-3.24, \mathrm{df}=64, p=1.91 \times 10^{-3}$; Figure $2 \mathrm{~d}$; Table S1A), suggesting that both measure related aspects of pollen fertility. Across all families, there were many large pollen grains (likely unreduced gametes) as well as a large number of empty pollen grains.

Female fertility is low in the hybrids, with an average of 2.12 seeds per head (range $=0-20$, standard deviation $=4.14$ ). There was a positive relationship between male and female fertility (Table S1A), most clearly seen as an increase in female fertility with a decrease in variance in pollen size (seeds per head $\sim \log$ (variance pollen diameter), slope $=-0.86, r^{2}=0.11, t=-2.78, \mathrm{df}=61$, $p=7.22 \times 10^{-3}$; Figure $2 \mathrm{~b}$ ). This relationship remained after standardizing seeds per head by disk area (nonparametric test of the correlation between variance in pollen size and seeds per head divided by disk area, Spearman's rho $=-0.316, \mathrm{~S}=60260, p=0.01, n=64$ ) eliminating the possibility that this association was an artifact of the positive relationship between disk diameter and seeds per head (which has slope $=0.12, r^{2}=0.0162, t=1.29, \mathrm{df}=99, p=0.20$ ). The relationship between pollen staining and female fertility was weaker and non-significant ( lope $=0.18, r^{2}=0.03, t=1.47, \mathrm{df}=61, p=0.14$ ), suggesting that this imprecise measure of pollen viability attenuated this signal. It may be that size uniformity indicates euploid gametes and an irregular shape indicates an aneuploid number.

The relationship between morphology and overall fertility was weak. At first glance, female fertility appeared to decrease slightly with perenniality (seeds per head: slope $=-0.22, r^{2}=0.03$, $t=-1.72, \mathrm{df}=99, p=0.09$ ). However, perennial index has no relationship with pollen size variance (slope $=0.019, r^{2}=0.002, t=0.34, \mathrm{df}=63, p=0.74$ ), and standardizing seeds per head by disk area nullified the near-significance between perennial index and female fertility (nonparametric test of the correlation between perennial index and seeds per head divided by disk area, Spearman's rho $=-0.113$, $\mathrm{S}=208551, p=0.256, n=103)$. Curiously, we found that pollen staining increased with perenniality (slope $=0.29, r^{2}=0.07, t=2.13, \mathrm{df}=63, p=0.04$ ), however, given the lack of biological mechanism, and the limited reliability of pollen staining as a measure of pollen viability, we are hesitant to draw strong conclusions from this observation. Additionally, the number of tests may increase the risk of false positive results due to multiple testing.

Finally, plants with more seeds per head also tended to have larger seeds (slope $=2.95, r^{2}=0.38$, $\left.t=7.70, \mathrm{df}=98, p=1.11 \times 10^{-11}\right)$, an indication that selection for overall fertility is harmonious with selection on seed size. No other morphological traits had significant relationships with male or female fertility (Table S1B, C).

\subsection{Changes in Traits over Time}

The $H$. annuus $\times H$. tuberosus breeding program has selected for classic domestication syndrome traits such as apical dominance, larger seeds, and more seeds per head in a perennial interspecific sunflower population. Due to the intermating strategy, a large within-generation variance has been maintained that allowed progress toward the ideotype to be made and slowed progress for other traits across generations (Figure 3, Table S2). The domestication approach focused on well-known characteristics to make the plant ideotype look more like $H$. annuus. The differential increase in the important traits is not unexpected due to the complex relationship between traits and the wide phenotypic variation within every generation.

Consistent with our breeding aims, seed size and apical dominance show some evidence of increasing across generations (seed widths: slope $=0.14, r^{2}=0.02, t=1.40, \mathrm{df}=108, p=0.16, \mathrm{IM}_{3} \mathrm{~F}_{1}$ generation mean: $2.8 \mathrm{~mm}$, range: $2.5-3.2 \mathrm{~mm}, \mathrm{IM}_{8} \mathrm{~F}_{1}$ generation mean: $3.9 \mathrm{~mm}$, range: $3-4.5 \mathrm{~mm}$; Flowers per plant: slope $=-0.089, r^{2}=0.01, t=-1.30, \mathrm{df}=126, p=0.20, \mathrm{IM}_{3} \mathrm{~F}_{1}$ generation mean: 41, range: $9-160, \mathrm{IM}_{8} \mathrm{~F}_{1}$ generation mean: 14 , range: $\left.2-27\right)$, though these results are not significant. However, male fertility shows an overall decline across generations with an increase in pollen size variance and decrease in pollen stainability (pollen variance: slope $=0.30, r^{2}=0.07, t=2.27, \mathrm{df}=64$, $p=0.03$; pollen staining: slope $=-0.20, r^{2}=0.22, t=-4.24, \mathrm{df}=64, p=7.44 \times 10^{-5}$; Figure $3 \mathrm{~b}$ ), suggesting that we are not effectively selecting for higher viability. 
Although we selected for perenniality by discarding plants lacking tubers, perenniality declined over generations (slope $=-0.09, r^{2}=0.08, t=-3.49 \mathrm{df}=132, p=6.68 \times 10^{-4}$, Figure $3 \mathrm{c}$ ), perhaps due to its negative correlation with other favorable traits (see below). Nonetheless, this trend appears to be driven by segregation for this trait, where the many individuals display complete perenniality loss, but the remaining individuals show vigorous tuber production.
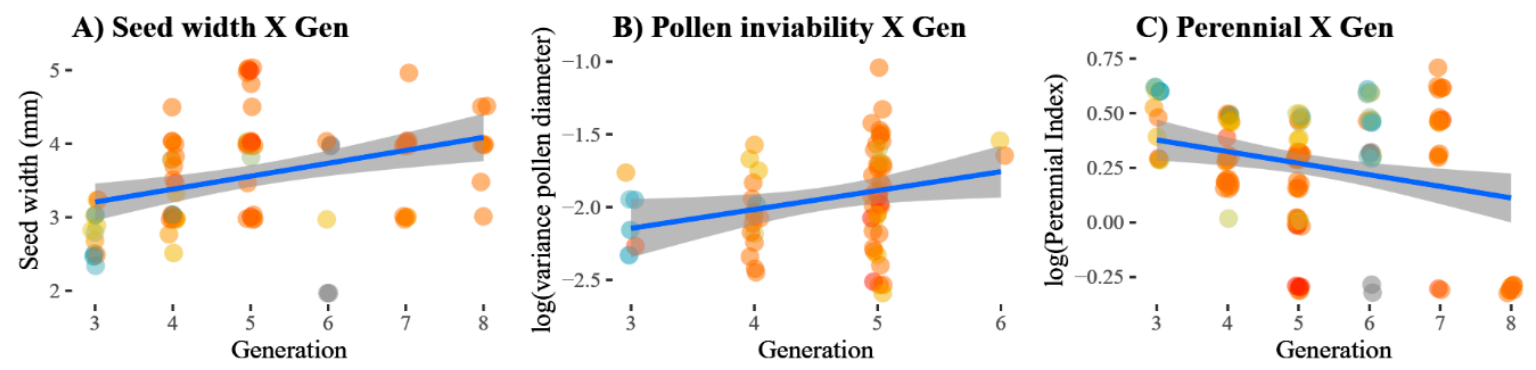

Figure 3. Over generations of intermating (A) selection for increased seed size shows progress, (B) male infertility is highly variable but increasing, and (C) perenniality segregates in later generations with a trend toward perenniality loss. Points are colored by maternal line. For breeding purposes, the outliers (individuals that are increasing in perenniality) are very important to balance the need for increased seed production with strong regrowth capacity. There is also a need to prevent new cultivars from becoming invasive.

\subsection{Negative Correlation Between Perenniality and Yield Traits}

Plants with a more annual phenotype in one trait tended to follow that general pattern across most traits. For example, plants with larger disk diameters tended to have fewer heads (indicating apical dominance) and large seeds, but less-robust root systems (Figure 4). Still, all traits display a high amount of variation (perennial index range: 0-5, disk diameter range: $1.5-7.4 \mathrm{~cm}$, seed width range: $2-5 \mathrm{~mm}$, disks per plants range: $1-197)$. Perennial index has a negative relationship with disk diameter (slope $=-0.45, r^{2}=0.40, \mathrm{t}=-9.18, \mathrm{df}=127, p=1.01 \times 10^{-15}$ ), seed size (slope $=-0.87$, $r^{2}=0.060, t=-2.64, \mathrm{df}=109, p=0.01$ ) and apical dominance (flowers per plant, slope $=0.66, r^{2}=0.08$, $t=3.37, \mathrm{df}=127, p=1.01 \times 10^{-3}$; Figure 4, Table S3A). Plants with larger disks tended to also have larger seeds (slope $=0.06, r^{2}=0.09, t=3.26, \mathrm{df}=109, p=1.49 \times 10^{-3}$ ), and both traits also show a positive (though non-significant) relationship with apical dominance (flowers per plant $\sim$ disk diameter, slope $=-0.31, r^{2}=0.01, t=-1.06, \mathrm{df}=127, p=0.29$; flowers per plant $\sim$ seed width, slope $=0.09$, $r^{2}=0.02, t=1.33, \mathrm{df}=109, p=0.19 ;$ Figure 4, Table S3B). Ideotype traits also tended to segregate by maternal line (ANOVA: disk diameter: $F_{17,108}=4.34, p=1.07 \times 10^{-6}$; flowers per plant: $F_{17,108}=1.45$, $p=0.13$; perennial index: $F_{18,113}=3.12, p=1.19 \times 10^{-4}$, seed width: $F_{16,92}=0.41, p=0.98$; Figure $4 \mathrm{~b}$, Table S4A).

Putative backcrosses to $H$. annuus were also encountered among our hybrids which showed several promising traits (male and female fertility, large seeds and large heads) but ultimately failed to develop tubers. 
A) Perrenial Index Reference Images

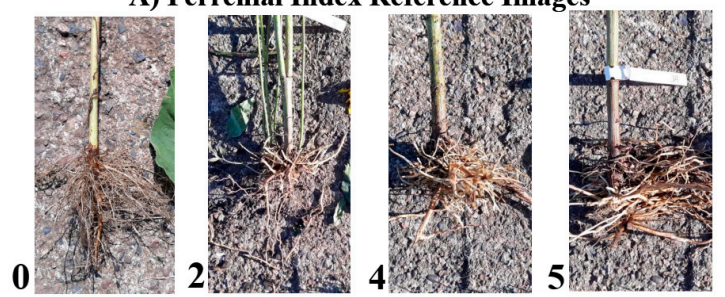

C) Favored traits decrease with perenniality
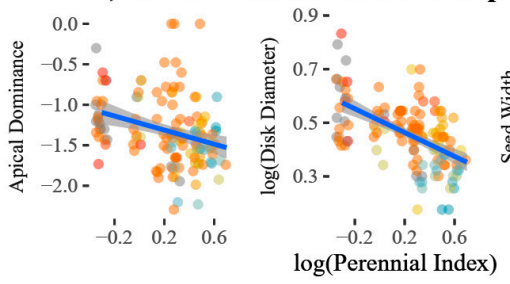

B) Trait variation across families

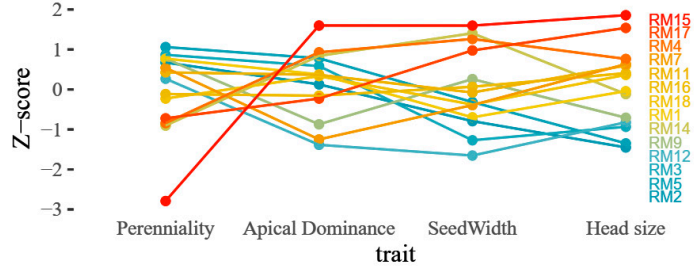

D) Other selected traits increase together

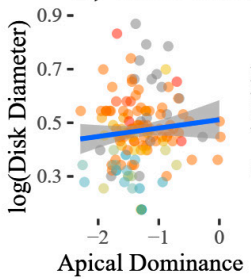

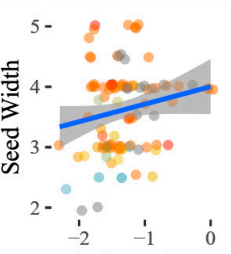

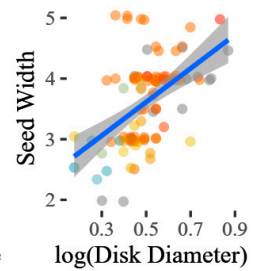

Figure 4. (A) Examples of below-ground morphologies scored by perennial index, increasing from left to right: H. annuus with a score of 0 , two hybrids with scores 2 and 4 , and H. tuberosus with the maximum score of 5 . Tubers, the overwintering structure, appear as swollen, light-colored "roots". Relationships between favored traits of hybrids (B) by maternal line, (C) compared to perenniality, and (D) compared across domesticated annual phenotypes. B-C: Colors indicate maternal line.

\subsection{Genomic Stability}

Major traits of interest have been male and female fertility as well as maintenance of the tetraploid genome size level. There was a large amount of genome size variability in the initial $\mathrm{F}_{1}$ population [31], which was not unexpected, as intraspecific variation in genome size has been widely reported [46]. With selection focused on meiotic stability (by keeping only tetraploid plants), ploidy has remained within the tetraploid range (max deviation estimate $=0.74 \mathrm{x}$ in $\mathrm{IM}_{7} \mathrm{~F}_{1}$, Figure 5), though deviations from tetraploidy show an increase across generations (slope $=0.11, r^{2}=4.94, t=4.84, \mathrm{df}=24, p=6.29 \times 10^{-5}$ ), which is to be expected given the genomic background of our population. Though less likely, it is also possible that contamination occurred in the seventh intermated generation, leading to larger deviations from tetraploidy.

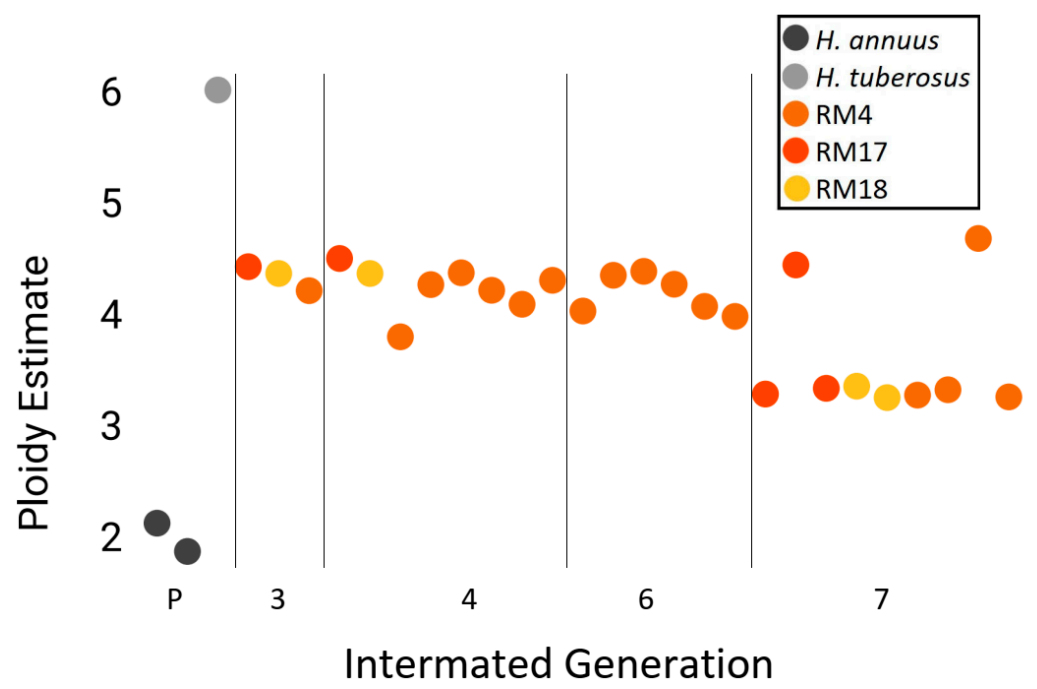

Figure 5. Genome size changes over intermating generations. " $\mathrm{P}$ " $=$ parent species. Colors indicate maternal line.

Finally, we explored whether selection for tetraploidy was a reliable way to predict fertility. If meiosis proceeds evenly from generation to generation, offspring should tend to have a complement 
of two H. divaricatus, one $H$. grosseserratus, and one H. annuus genomes $(2 n=4 x=68)$. Therefore, we posited that deviations from $4 \mathrm{x}$ result from meiotic instabilities that also affect fertility. However, despite selection for genome size similarity, deviation from tetraploidy did not predict fertility or morphological traits (Table S5). Interestingly, we observed slight differences in the deviation from tetraploidy between the three maternal lines whose genomes were measured (ANOVA $F_{2,23}=2.70$, $p=0.09$; Table S4B).

\section{Discussion}

\subsection{Fertility}

$H$. annuus $\times H$. tuberosus hybrids are known to exhibit irregular meiosis $[33,37,38]$, so the inconsistent fertility we observed across generations was as we expected. Interspecific crosses and neopolyploids often experience lethal meiotic imbalances due to multivalent and univalent formation (i.e., too many or too few chromosomes held together by crossovers during meiosis), nondisjunction, or lagging chromosomes which can cause aneuploidy, gametic non-reduction, and cytomixis [47,48]. Such aberrations must underlie the low fertility, as well as the high frequency of large pollen grains (likely unreduced gametes) and empty pollen grains observed in our hybrids. Variable pollen was also observed in intergeneric hybrids of Selenicereus (an allopolyploid) and Hylocereus (diploid; colloquially, vine cacti or dragon fruit; [49,50]) and in interspecific hybrids within the Lotus genus [51]. Encouragingly though, aneuploidy is expected to decline over generations as polyploids evolve to undergo meiosis more similarly to their diploid progenitors through strong selection on meiotic proteins [47].

\subsection{Pairing Structure of Trigenomic Tetraploids}

It seems likely that the meiotic abnormalities and low fertility seen in $H$. annuus $\times H$. tuberosus hybrids $[33,34,37,38,52-54]$ arise due to the distant relationship between $H$. annuus (the C-genome) and all other genomes (especially the B-genome, $H$. grosseserratus). Meiosis in the progenitor $H$. tuberosus is relatively stable (e.g., $\mathrm{A}_{1} \mathrm{~A}_{1} \mathrm{~A}_{2} \mathrm{~A}_{2} \mathrm{BB}$ ) $[33,37,38,55]$, and earlier work anticipated that combining a set of $H$. annuus chromosomes with the $H$. tuberosus complex might result in a tetraploid with homologous $H$. divaricatus (A-genome) chromosomes pairing with one another and the remaining sets pairing as well (i.e., $A_{1} A_{2} B_{1} B_{2}$ ), assuming a close relationship and sufficient homology between the B-genome and that of $H$. annuus $[31,33,56]$. However, later work revealed that the B subgenome of $H$. tuberosus actually descends from $H$. grosseserratus [40], a perennial sunflower with a more distant homeologous relationship to $H$. annuus. The arrangement of subgenomes within our hybrids is therefore more aptly described as $\mathrm{A}_{1} \mathrm{~A}_{2} \mathrm{BC}$; a predicament that likely underlies the meiotic abnormalities seen in the hybrids. Analogously, aberrations are common during autosyndetic and allosyndetic associations (recombination between different chromosomes of the same sub-genome or between $\mathrm{B}$ and $\mathrm{C}$ homeologs, respectively) during meiosis in interspecific AA BC Brassica hybrids [57].

Incompatibilities inherent in distant-relative pairing may explain why, even though we selected for plants with a tetraploid genome size, fertility problems remain unresolved. Tetraploidy does not appear to guarantee meiotic compatibility between subgenomes, or fertility. The high degree of observed vegetative and reproductive phenotypic variability of our hybrids may be explained by structural variation among recombinant or segregating perennial and annual subgenomes due to chromosome loss, allosyndesis, or balanced segregation of non-exchange pairs $[58,59]$ which may differ from cross to cross. Since such structural variants would be passed down maternal lines, this hypothesis (that structural variation proliferates in our population) finds possible support in slight differences in the deviation from tetraploidy between the three maternal lines whose genomes were measured.

In our population, successful crosses are likely achieved (1) in the absence of recombination, with segregation fidelity between non-exchange homeologs (as described in [60]) or (2) via allosyndesis, either with or without some level of multivalent and univalent formation between homeologs. Going 
forward, closer attention to patterns in inbred- vs. between-maternal-line crosses may be appropriate, and seeds per head may be a better proxy for overall fertility than is ploidy fidelity. Further, a future study identifying the genomic components of later-generation hybrids could reveal the meiotic behavior underlying successful crosses (e.g., How common is recombination in individuals, among maternal lines, or in particular chromosomes?) and help identify individuals which would likely have higher fertility levels or cross-compatibility.

\subsection{Toward the Ideotype}

We observed slight increases in seed size and apical dominance over generations, which is encouraging and implies that there is sufficient variation within our population for selection to work. However, we also found that hybrids with vigorous tuber growth tend to have smaller composite heads with smaller seeds, while plants producing a single large head with large seeds tend to produce less-robust tubers (though we note that plants with lower perennial indices are often cold-hardy, though not as vigorous as those with higher indices). Though the apparent antagonism between desired above-ground (apical dominance, large seeds, and large heads) and below-ground morphologies (tuber production) has been an obstacle toward achieving the ideotype, a closer look at the data reveal abundant phenotypic variation (e.g., see the scatter in Figure 4 C,D.). There is variance in individuals and across maternal lines, and this implies that stronger pollen control may lead to a better response to selection. This means that we can likely continue to make progress, for example, by choosing plants with large seeds and high seed set (which have a positive relationship) that also show sufficient perenniality.

\section{Conclusions}

While the high degree of vegetative and reproductive phenotypic variability has led to variable gains, it still provides several different ways of moving forward; the first is to continue intermating successive generations, removing old individuals from the breeding population so that selection on meiosis can be more effective and more direct [61,62]. Since plants are perennial, when subsequent generations do not produce the desired results $\left(\mathrm{IM}_{7} \mathrm{~F}_{1}\right.$ and $\left.\mathrm{IM}_{8} \mathrm{~F}_{1}\right)$, we can cross them back to previous generations to reintroduce beneficial characteristics. Additionally, more stringent pollen control could be used, specifically sib-mating of individuals that show stability [63]. Finally, there is potential with ploidy manipulation to double the chromosome number creating an octoploid [33], however this could potentially bottleneck the population limiting variance for future breeding. Selection for fertility (and thus, meiotic stability) should be strong as it has been shown to be successful [64], and should be the primary focus before improving agronomic traits. Further, the sunflower genome [65] could be used in combination with low-coverage whole genome sequencing to identify individuals that are likely to have proper pairing during meiosis, thus providing better information to select parents. While selection works, not surprisingly, parental selection and clear selection targets improve progress towards perennial ideotypes.

Supplementary Materials: The following are available online at http://www.mdpi.com/2073-4395/9/11/704/s1, Table S1: Fertility traits, Table S2: Traits across generations, Table S3: Ideotype, Table S4: Maternal lines, Table S5: Deviation from tetraploidy, Methods S1: R code, and Data.

Author Contributions: Conceptualization, K.J.B., A.C.H., R.M.S., D.L.W. and M.B.K.; Data curation, J.M.E. and K.J.B.; Formal analysis, J.M.E. and Y.B.; Funding acquisition, R.M.S. and Y.B.; Investigation, J.M.E.; Methodology, J.M.E. and K.J.B.; Project administration, J.M.E.; Resources, R.M.S. and Y.B.; Supervision, R.M.S., Y.B. and M.B.K.; Visualization, J.M.E. and Y.B.; Writing - original draft, J.M.E.; Writing - review \& editing, J.M.E., Y.B. and M.B.K.

Funding: This work was supported by the University of Minnesota Forever Green Initiative and the University of Minnesota Varietal Development Fund and HATCH award 71-055 and MN Department of Agriculture Award Number CON000000057187.

Acknowledgments: We thank three anonymous reviewers whose comments improved this paper. 
Conflicts of Interest: The authors declare no conflict of interest. The funders had no role in the design of the study; in the collection, analyses, or interpretation of data; in the writing of the manuscript, or in the decision to publish the results.

\section{References}

1. Tilman, D.; Balzer, C.; Hill, J.; Befort, B.L. Global food demand and the sustainable intensification of agriculture. Proc. Natl. Acad. Sci. USA 2011, 108, 20260-20264. [CrossRef] [PubMed]

2. Hickey, L.T.; Hafeez, A.N.; Robinson, H.; Jackson, S.A.; Leal-Bertioli, S.C.M.; Tester, M.; Gao, C.; Godwin, I.D.; Hayes, B.J.; Wulff, B.B.H. Breeding crops to feed 10 billion. Nat. Biotechnol. 2019, 37, 744-754. [CrossRef] [PubMed]

3. Knapp, S.; Van Der Heijden, M.G.A. A global meta-analysis of yield stability in organic and conservation agriculture. Nat. Commun. 2018, 9, 3632. [CrossRef] [PubMed]

4. Knowler, D.; Bradshaw, B. Farmers' adoption of conservation agriculture: A review and synthesis of recent research. Food Policy 2007, 32, 25-48. [CrossRef]

5. Kassam, A.; Friedrich, T.; Derpsch, R. Global spread of Conservation Agriculture. Int. J. Environ. Stud. 2019, 76, 29-51. [CrossRef]

6. Rockström, J.; Williams, J.; Daily, G.; Noble, A.; Matthews, N.; Gordon, L.; Wetterstrand, H.; DeClerck, F.; Shah, M.; Steduto, P.; et al. Sustainable intensification of agriculture for human prosperity and global sustainability. Ambio 2017, 46, 4-17. [CrossRef]

7. Kantar, M.B.; Tyl, C.E.; Dorn, K.M.; Zhang, X.; Jungers, J.M.; Kaser, J.M.; Schendel, R.R.; Eckberg, J.O.; Runck, B.C.; Bunzel, M.; et al. Perennial Grain and Oilseed Crops. Annu. Rev. Plant Boil. 2016, 67, 703-729. [CrossRef]

8. Robertson, G.P. Greenhouse Gases in Intensive Agriculture: Contributions of Individual Gases to the Radiative Forcing of the Atmosphere. Science 2000, 289, 1922-1925. [CrossRef]

9. Sperow, M.; Eve, M.; Paustian, K. Potential Soil C Sequestration on U.S. Agricultural Soils. Clim. Chang. 2003, 57, 319-339. [CrossRef]

10. Culman, S.W.; Snapp, S.S.; Ollenburger, M.; Basso, B.; DeHaan, L.R. Soil and Water Quality Rapidly Responds to the Perennial Grain Kernza Wheatgrass. Agron. J. 2013, 105, 735. [CrossRef]

11. Cox, T.S.; Glover, J.D.; Van Tassel, D.L.; Cox, C.M.; DeHaan, L.R. Prospects for Developing Perennial Grain Crops. BioScience 2006, 56, 649. [CrossRef]

12. Glover, J.D.; Reganold, J.P.; Bell, L.W.; Borevitz, J.; Brummer, E.C.; Buckler, E.S.; Cox, C.M.; Cox, T.S.; Crews, T.E.; Culman, S.W.; et al. Increased Food and Ecosystem Security via Perennial Grains. Science 2010, 328, 1638-1639. [CrossRef] [PubMed]

13. Kell, D.B. Breeding crop plants with deep roots: Their role in sustainable carbon, nutrient and water sequestration. Ann. Bot. 2011, 108, 407-418. [CrossRef] [PubMed]

14. Kort, J.; Collins, M.; Ditsch, D. A review of soil erosion potential associated with biomass crops. Biomass Bioenergy 1998, 14, 351-359. [CrossRef]

15. Gyssels, G.; Poesen, J.; Bochet, E.; Li, Y. Impact of plant roots on the resistance of soils to erosion by water: A review. Prog. Phys. Geogr. Earth Environ. 2005, 29, 189-217. [CrossRef]

16. Randall, G.; Goss, M. Nitrate Losses to Surface Water through Subsurface, Tile Drainage. In Nitrogen in the Environment: Sources, Problems and Management; Follett, R.F., Hatfield, J.L., Eds.; Elsevier: Amsterdam, The Netherlands, 2001; pp. 95-122.

17. Meyer, R.S.; Duval, A.E.; Jensen, H.R. Patterns and processes in crop domestication: An historical review and quantitative analysis of 203 global food crops. New Phytol. 2012, 196, 29-48. [CrossRef]

18. Gaut, B.S.; Díez, C.M.; Morrell, P.L. Genomics and the Contrasting Dynamics of Annual and Perennial Domestication. Trends Genet. 2015, 31, 709-719. [CrossRef]

19. Kantar, M.B.; Nashoba, A.R.; Anderson, J.E.; Blackman, B.K.; Rieseberg, L.H. The Genetics and Genomics of Plant Domestication. BioScience 2017, 67, 971-982. [CrossRef]

20. Lye, Z.N.; Purugganan, M.D. Copy Number Variation in Domestication. Trends Plant Sci. 2019, 24, 352-365. [CrossRef] 
21. Runck, B.C.; Kantar, M.B.; Jordan, N.R.; Anderson, J.A.; Wyse, D.L.; Eckberg, J.O.; Barnes, R.J.; Lehman, C.L.; DeHaan, L.R.; Stupar, R.M.; et al. The Reflective Plant Breeding Paradigm: A Robust System of Germplasm Development to Support Strategic Diversification of Agroecosystems. Crop Sci. 2014, 54, 1939-1948. [CrossRef]

22. DeHaan, L.R.; Van Tassel, D.L.; Anderson, J.A.; Asselin, S.R.; Barnes, R.; Baute, G.J.; Cattani, D.J.; Culman, S.W.; Dorn, K.M.; Hulke, B.S.; et al. A Pipeline Strategy for Grain Crop Domestication. Crop Sci. 2016, 56, 917. [CrossRef]

23. Fernie, A.R.; Yan, J. De Novo Domestication: An Alternative Route toward New Crops for the Future. Mol. Plant 2019, 12, 615-631. [CrossRef] [PubMed]

24. DeHaan, L.; Christians, M.; Crain, J.; Poland, J. Development and Evolution of an Intermediate Wheatgrass Domestication Program. Sustainability 2018, 10, 1499. [CrossRef]

25. Van Tassel, D.L.; Albrecht, K.A.; Bever, J.D.; Boe, A.A.; Brandvain, Y.; Crews, T.E.; Gansberger, M.; Gerstberger, P.; González-Paleo, L.; Hulke, B.S.; et al. Accelerating Domestication: An Opportunity to Develop New Crop Ideotypes and Breeding Strategies Informed by Multiple Disciplines. Crop Sci. 2017, 57, 1274. [CrossRef]

26. Braun, L.; Gillman, J.; Hoover, E.; Russelle, M. Nitrogen fertilization for young established hybrid hazelnuts in the Upper Midwest of the United States of America. Can. J. Plant Sci. 2011, 91, 907-918. [CrossRef]

27. Wilkins, P.W.; Humphreys, M.O. Progress in breeding perennial forage grasses for temperate agriculture. J. Agric. Sci. 2003, 140, 129-150. [CrossRef]

28. Karp, A.; Hanley, S.J.; Trybush, S.O.; MacAlpine, W.; Pei, M.; Shield, I. Genetic Improvement of Willow for Bioenergy and BiofuelsFree Access. J. Integr. Plant Boil. 2011, 53, 151-165. [CrossRef]

29. Allwright, M.R.; Taylor, G.; Information, P.E.K.F.C. Molecular Breeding for Improved Second Generation Bioenergy Crops. Trends Plant Sci. 2016, 21, 43-54. [CrossRef]

30. Kantar, M.B.; Hüber, S.; Herman, A.; Bock, D.G.; Baute, G.; Betts, K.; Ott, M.; Brandvain, Y.; Wyse, D.; Stupar, R.M.; et al. Neo-Domestication of an Interspecific Tetraploid $\times$ Population That Segregates for Perennial Habit. Genes 2018, 9, 422. [CrossRef]

31. Kantar, M.; Betts, K.; Michno, J.-M.; Luby, J.J.; Morrell, P.L.; Hulke, B.S.; Stupar, R.; Wyse, D.L. Evaluating an interspecific Helianthus annuus $\times$ Helianthus tuberosus population for use in a perennial sunflower breeding program. Field Crops Res. 2014, 155, 254-264. [CrossRef]

32. Ščibria, N.A. Hybrids between the Jerusalem artichoke (Helianthus tuberosus L.) and the sunflower(Helianthus annuus L.). C.R. Doklady L'Académie Sci. L'URSS 1936, 11, 193-196.

33. Kostoff, D. Autosyndesis and structural hybridity in F1-hybrid Helianthus tuberosus L. x Helianthus annuus L. and their sequences. Genetica 1939, 21, 285-300. [CrossRef]

34. Heiser, C.B.; Smith, D.M. Species crosses in Helianthus: II. Polyploid species. Rhodora 1964, 66, $344-358$.

35. Carter, J.F.; Whelan, E.D.P. Cytology and Interspecific Hybridization; American Society of Agronomy: Madison, WI, USA, 1978.

36. Cauderon, $\mathrm{Y}$. Selection pour la resistance au mildiou du tournesol a partir d'hybrides topinambour $\mathrm{x}$ tournesol. Ann. Améliof. Plantes 1970, 20,363-373.

37. Atlagic, J.; Dozet, B.; Škorić, D. Meiosis and Pollen Viability in Helianthus tuberosus L. and its Hybrids with Cultivated Sunflower. Plant Breed. 1993, 111, 318-324. [CrossRef]

38. Atlagic, J.; Terzic, S. Cytogenetic study of hexaploid species Helianthus tuberosus and its F1 and BC1F1 hybrids with cultivated sunflower, H. annuus. Genetika 2006, 38, 203-213. [CrossRef]

39. Hulke, B.S.; Wyse, D.L. Using interspecific hybrids with Helianthus tuberosus L. to transfer genes for quantitative traits into cultivated sunflower, H. annuus L. In Proceedings of the 17th International Sunflower Conference, Cordoba, Spain, 8-12 June 2008; pp. 729-734.

40. Bock, D.G.; Kane, N.C.; Ebert, D.P.; Rieseberg, L.H. Genome skimming reveals the origin of the Jerusalem Artichoke tuber crop species: Neither from Jerusalem nor an artichoke. New Phytol. 2014, 201, 1021-1030. [CrossRef]

41. Donald, C.M. The breeding of crop ideotypes. Euphytica 1968, 17, 385-403. [CrossRef]

42. Miller, J.; Gulya, T.; Vick, B. Registration of Two Maintainer (HA 434 and HA 435) and Three Restorer (RHA 436 to RHA 438) High Oleic Oilseed Sunflower Germplasms. Crop Sci. 2004, 44, 1034. [CrossRef]

43. Peterson, R.; Slovin, J.P.; Chen, C. A simplified method for differential staining of aborted and non-aborted pollen grains. Int. J. Plant Boil. 2010, 1, 13. [CrossRef] 
44. Singhal, V.K.; Kumar, P. Impact of cytomixis on meiosis, pollen viability and pollen size in wild populations of Himalayan poppy (Meconopsis aculeata Royle). J. Biosci. 2008, 33, 371-380. [CrossRef] [PubMed]

45. R Core Team. A Language and Environment for Statistical Computing; R Core Team: Vienna, Austria, 2017.

46. Realini, M.F.; Poggio, L.; Cámara-Hernández, J.; González, G.E. Intra-specific variation in genome size in maize: Cytological and phenotypic correlates. AoB Plants 2016, 8, lv138. [CrossRef] [PubMed]

47. Bomblies, K.; Higgins, J.D.; Yant, L. Meiosis evolves: Adaptation to external and internal environments. New Phytol. 2015, 208, 306-323. [CrossRef] [PubMed]

48. Cisneros, A.; Tel-Zur, N. Evaluation of Interspecific-Interploid Hybrids (F1) and Back Crosses (BC1) in Hylocereus Species (Cactaceae). Meiosis Mol. Mech. Cytogenet. Divers. 2012. [CrossRef]

49. Tel-Zur, N. Chromosome Doubling in Vine Cacti Hybrids. J. Hered. 2003, 94, 329-333. [CrossRef] [PubMed]

50. Tel-Zur, N.; Abbo, S.; Bar-Zvi, D.; Mizrahi, Y. Clone identification and genetic relationship among vine cacti from the genera Hylocereus and Selenicereus based on RAPD analysis. Sci. Hortic. 2004, 100, 279-289. [CrossRef]

51. De Nettancourt, D.; Grant, W.F. La Cytogénétique de Lotus (Leguminosae). Cytologia 1964, 29, $191-195$. [CrossRef]

52. Cauderon, Y. Analyse cytogénétique d'hybrides entre Helianthus tuberosus et H. annuus: Conséquences en matière de sélection. Ann. L'amélioration Plantes 1965, 15, 243-261.

53. Ustinova, E.I. Study of interspecies hybrids, Helianthus annuus L. $\times$ Helianthus tuberosus L. Byul. Moskov Obshchest. Ospytatelei Prirody Otd. Biol. 1966, 71, 100-106.

54. Cedeno, J.R.; McMullen, M.S.; Miller, J.F. Cytogenetic relationship between Helainthus annuus L. and H. tuberosus L. In Proceedings of the 11th International Sunflower Conference, Mar del Plata, Argentina, 10-13 March 1985; pp. 541-546.

55. Kostoff, D. A contribution to the meiosis of Helianthus tuberosus L. Z. Pflanzenzuchtg. 1934, 19, $423-438$.

56. Anisimova, I.N. On the nature of polyploid genomes of sunflower species. Bull. N. I. Vavilov Inst. Plant Ind. 1982, 118, 27-29.

57. Mason, A.S.; Huteau, V.; Eber, F.; Coriton, O.; Yan, G.; Nelson, M.N.; Cowling, W.A.; Chèvre, A.-M. Genome structure affects the rate of autosyndesis and allosyndesis in AABC, BBAC and CCAB Brassica interspecific hybrids. Chromosom. Res. 2010, 18, 655-666. [CrossRef] [PubMed]

58. Ramsey, J.; Schemske, D.W. Neopolyploidy in Flowering Plants. Annu. Rev. Ecol. Syst. 2002, 33, 589-639. [CrossRef]

59. Gaeta, R.T.; Chris Pires, J. Homoeologous recombination in allopolyploids: The polyploid ratchet. New Phytol. 2010, 186, 18-28. [CrossRef] [PubMed]

60. Boumil, R.M.; Kemp, B.; Angelichio, M.; Nilsson-Tillgren, T.; Dawson, D.S. Meiotic segregation of a homeologous chromosome pair. Mol. Genet. Genom. 2003, 268, 750-760.

61. Santos, J.L.; Alfaro, D.; Sanchez-Moran, E.; Armstrong, S.J.; Franklin, F.C.H.; Jones, G.H. Partial diploidization of meiosis in autotetraploid Arabidopsis thaliana. Genetics 2003, 165, 1533-1540.

62. Srivastava, S.; Lavania, U.C. Meiotic Regularization, Restoration of Seed Fertility and Alkaloid Content in the Induced Autotetraploids of Hyoscyamus albus L. Plant Breed. 1990, 104, 160-166. [CrossRef]

63. Hilpert, G. Effect of selection for meiotic behaviour in autotetraploid rye. Hereditas 1957, 43, 318-322. [CrossRef]

64. Bomblies, K.; Jones, G.; Franklin, C.; Zickler, D.; Kleckner, N. The challenge of evolving stable polyploidy: Could an increase in "crossover interference distance" play a central role? Chromosoma 2016, 125, 287-300. [CrossRef]

65. Badouin, H.; Gouzy, J.; Grassa, C.J.; Murat, F.; Staton, S.E.; Cottret, L.; Lelandais-Brière, C.; Owens, G.L.; Carrère, S.; Mayjonade, B.; et al. The sunflower genome provides insights into oil metabolism, flowering and Asterid evolution. Nature 2017, 546, 148-152. [CrossRef]

(C) 2019 by the authors. Licensee MDPI, Basel, Switzerland. This article is an open access article distributed under the terms and conditions of the Creative Commons Attribution (CC BY) license (http://creativecommons.org/licenses/by/4.0/). 